\title{
Practice Teaching Assumptions on CNC Cutting by VB Visualization Software
}

\author{
$\mathrm{Min} \mathrm{Hu}$ \\ Jiangsu province xuzhou technician institute \\ Xuzhou, Jiangsu 221151, China \\ 331947080@qq.com
}

\begin{abstract}
This article starts with the analysis of the development and requirements of numeric control technology combined with numeric control training teaching in vocational schools. It analyzes the research status of visualization technology and probes the application of VB programming language in educational and teaching areas. Under the circumstances of new curriculum reforms carried out in vocational schools, I have researched the advantages of numeric control cutting teaching by applying visualization technology combined with VB programming language to numeric control teaching. I have also designed and developed interactive teaching software aimed at numeric control cutting teaching practice. Also I have developed the interactive interfaces which are based on educational scheme and the teaching guidelines, by analyzing the characteristics of three-year-program intermediate students from Class 1, 2014 welding department. Besides, take the board operation in the numeric control cutting operation as an example, I have expounded in brief that we can employ many different teaching methods and modern teaching means to carry out teaching reforms. By comparing traditional teaching methods with interactive teaching methods, I have proved that visualized teaching and interactive teaching can improve our teaching efficiency and apply to the learning characteristics of modern students and they also play a certain roles in improving students' learning interest and cultivating students' strong manipulative abilities. And thus they can help students to learn to operate and program and make them all-around skilled talents. In addition, they also play a positive role in promoting numeric control cutting integrated teaching.
\end{abstract}

Keywords—VB; visualization; CNC cutting practice teaching

\section{INTRODUCTION}

CNC is the technology which uses digital information on the mechanical movement process and the working state of the control technology, mainly used in computer operation technology, sensor detection technology, network technology, machinery manufacturing technology and modern control technology [1]. The reason why it is widely used in various fields is the high precision characteristics which can achieve high efficiency, flexibility of the automated production line. IN the rapid development of manufacturing today, the level of manufacturing automation reflects the level of national economic development and production [2]. Whether the enterprise has a flexible automation, integrated, intelligent production line has become an important indicator of the enterprises.
With the development of numerical control technology[3], the whole CNC cutting industry has been developed from the manual semi-automatic cutting to the flame plasma $\mathrm{CNC}$ cutting, water knife, laser robot cutting, its technical experience has combined with CNC cutting technology, computer hardware and software technology, flame cutting technology and precision machinery into a high-tech industry. $\mathrm{NC}$ cutting and other cutting methods can effectively improve the use of sheet metal utilization, cutting quality and sheet utilization, but also can reduce the labor intensity of the operation.

In the machining industry, $\mathrm{CNC}$ cutting is called steel tailor, so it becomes the key process of metal material processing. However, it is difficult for the enterprise to recruit the person who has the ability of both CNC cutting technology skills and programming. There are many reasons, and now most of the students are the only one child, the lack of hardworking spirit. Even some of them have stepped into the enterprise it is because the lacking of professionalism leads them still difficult to stick to their posts.

We start from the curriculum development, change the teaching model, in order to meet the development of modern vocational education, we combine with the new training model of vocational school, for the characteristics of secondary vocational students, cultivate a multi-dimensional perspective of the skills talent. VB software will be combined with curriculum features to develop visual interactive software applied to teaching to improve the effectiveness of CNC cutting practice teaching. It is a good step for the better integration into the combination of learning.

\section{VISUAL BASIC}

VB (Visual Basic) is a Windows application development tool which Microsoft Corporation launched in 1991.VB language is a high-level language which is actuated by the event driver and it is objectivism and structured. For noncomputer professional programmers[4], the use of VB for program development or visualization system development is a good choice. Because VB is very convenient to develop graphical user interface and has a lot of common controls and Active controls which can be set by the operation features of $\mathrm{CNC}$ cutting. The control on the interface is driven by the mouse or keyboard events. VB has better compatibility which can also call other functions or other programs, such as MATLAB. Because of its powerful interface setting function, 
so the use of VB can achieve graphics and man-machine dialogue interactive teaching system.

\section{VISUALIZATION TECHNOLOGY}

It is estimated that the channel broadband of People's visual data is up to $2 \mathrm{~GB}$ per second.Half of brain's neural cells is applied for dealing with visual input information.which Visualization fully utilizes people's eye-brain system with the fastest speed and widest band function to deal and understand all kinds of information. Visualization can fully exert students' image thinking with its intuition and vitality and other characteristics with a good application prospect.There is still a distance for our national Visualization technique with a late start. The study on it conducted from below two sides:

Firstly, Research on the process development of Visualization technique and visual tools development for various fields. For example : the paper "design and implementation of visual tools for $\mathrm{C}$ Programming Language program structure " explains how to develop visual tools in the light of program structure Visualization.

Secondly,Specific application and study on Visualization in different fields and topics. For example : in the paper of "application research in teaching on Visual tools -Visual Eyes "Author make a detailed introduction aiming at Visual tools Visual Eyes. The paper mainly sketches its development,the project construct schematic of Visual Eyes then at last,experiment on two classes chosen to conclude the results.

Currently,Visual teaching software and tools abroad are mainly Macromedia Author ware,IWB Web CT,Learning SpaceVisual Eyes etc.while there are some kinds of visual software in china,such as PowerPoint, Flash, Founder Author Tool、Kaidi Guangzhou and so on,which offers us great help in our teaching ignoring its disadvantage. These visual tools is easy to learn, while the software such as PowerPoint, course ware master is widely used in education teaching with its strong practicability and easy to master;for another software, as it is hard to use for non-computer teachers as you need some computer programming knowledge, so there is no popularization. But in general, the development of visual software promotes the teaching method's change and improves teaching efficiency.

\section{ThE PRESENT SituATION OF VisUALIZATION AND VB COMBINATION}

Domestic education experts in the field of education and teaching will be VB and visualization of the combination of examples. There are lots of examples which domestic education experts has applied in the combination with VB and visualization.

In 2004, Zeng Min of Central South University of Forestry and Technology studied and developed the visual design parameters of panel furniture based on VB[5], In 2005, Gao Hua from Shandong University studied and developed the geometric simulation system of NC cutting based on VB, In 2007, Li Qiang of Taiyuan University of Technology studied the visualization algorithm based on the control of visualization algorithm[6], In 2007, Liu Yong bo of Electronic Science and Technology University made a secondary development system design for AutoCAD based on VB[7], In 2009 Jiang Xiao wei from China Mining University made a exploitation and application about MATLAB vibration simulation system based on VB, In 2011,Deng daoji from Fuzhou University analyzed and studied the parametric modeling and finite element analysis of the port gantry crane based on VB. In 2014 Ruan Zongli from China University of Petroleum develop a "numerical calculation method" support software for teaching which combined MATLAB with VB [8]. In order to develop teaching resources and change the traditional teaching mode in the past, so far, for the field of $\mathrm{CNC}$ cutting professional visualization of VB is almost blank, so the combination of VB and visualization applied to the teaching of CNC cutting is necessary.

\section{THE ADVANTAGES OF VISUALIZATION TECHNOLOGY IN TEACHING}

Using the interactivity of visualization technology can realize the animation demonstration and the teaching content switching, Students deepen the NC cutting practice course theory by falsh and Simulation demonstration.In addition[9],Students can seen the different of observations by change the Workpiece and machine parameters ,which have contributed to understand the process and operation of setting machine parameters

Students recognized the concept of what you have learned by begin the class, and they have understand the concept by flash and graph,and so on.Not only visualize the concept of knowledge and the process of evolution, but also help to enhance the students' interest in learning. CNC cutting practice teaching, practice teaching workshop equipment Co., in poor environment, the workshop type of work, the noise is big, so the practice in the classroom setting of multimedia case, we can divide the CNC cutting visualization software will reproduce the practice field, which helps students understand the related knowledge and understanding of the image after cutting.

After a detailed explanation by the teacher, students can watch the video animation repeatedly according to their own acceptance, until they do not understand the knowledge points so that it can help students improve their independent learning ability. In addition, the visual teaching can also be separated from the classroom environment, students can transfer knowledge through the network, and at home can also review and consolidate the knowledge learned. Therefore, the visual teaching method has changed the traditional teaching mode and improved the teaching efficiency. It is a new teaching method which is worth popularizing.

\section{THE APPLICATION OF VB VISUALIZATION IN THE NUMERICAL CONTROL CUTTING COURSE}

As being set up in secondary vocational school for numerical control cutting, this course aims to train students on their ability to learn knowledge and to use it into practice, and the professional spirit. While for the knowledge application ability, this project pays attention to cultivate students' ability to operate $\mathrm{CNC}$ cutting machine, as well as the special programming ability to use nesting software. Course contents are arranged as following: 


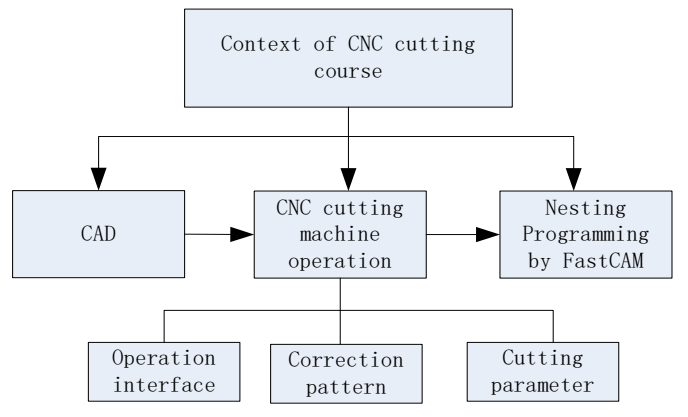

Fig. 1 Course content

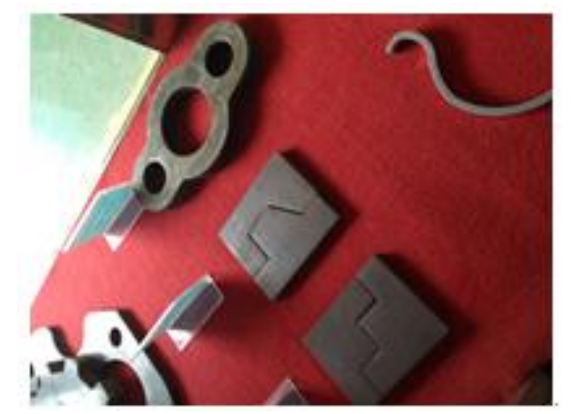

Fig. 2 Physical graphics

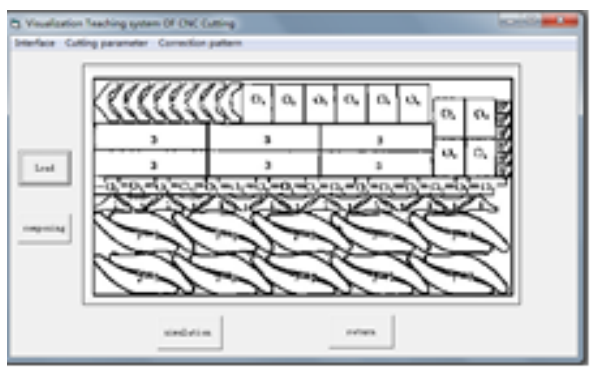

Fig. 3 VB visualization window

Taking on-board operation project in teaching module of CNC cutting off machine as example, this project studies the visualization teaching methods. Mainly using graphic method, problem guiding method, task driven method, and autonomous inquiry method, this project aims to develop the skilled talents that can independently program and make numerical control cutting and blanking.

Firstly, using graphic method, As shown in figure 2, we guide the student to see the video and photos, and ask questions after careful observation. For example, for the same piece of steel plate, why the blanking results are not the same? In this way, we inspire students to think by themselves. What can we do to save material and improve the cutting efficiency? By comparing actual entity with graphics, we guide students to understand the purpose and role of on-board, and make clear of the tasks.Secondly, release task specification. And using task driving method, distribute the tasks to students that are divided into groups. Based on the knowledge of machine tool interface function, and after the analysis and group discussions that can help students gain knowledge of on-board operation steps, students can searching for all information independently. Thus, we can cultivate students' autonomous learning ability as well as the team cooperation ability.

Then, each group members make simulation exercise through computer visual interactive interface. As shown in figure 3, the VB visualization window can help to manage and optimize the graphics drew by students. By re-arranging the graphics of different sizes and dimensions, it can help to make the most of the utilization rate of steel plate, to lay a good foundation for the numerical control blanking. Also there would be role exchange within the team in the process of operation, to improve the ability of collaboration, and everyone has the opportunity to operate.

At last, students evaluate and share their operating experience and insufficiency for the operating of $\mathrm{VB}$ visualization window, and list improvement ideas accordingly. Also the teacher evaluates the performance of each group, and inspires the improvement of students' learning enthusiasm and motivation.

The research had been made based on the 30 students of Welding-14 class, for the comparison of traditional teaching and visual teaching. The results showed that the use of visualization in the teaching of numerical control cutting, improved the teaching quality and teaching effect greatly.

\section{SUMMARY}

To sum up,According to the character of education method,summarized under the traditional model, we get the concept of visualizing education, and expand the merit of visualizing education which is combined with $\mathrm{NC}$ cutting in practical education. It changed the situation of all kinds of difficulties in original class, like tough organization and discipline, tough teaching contents, and difficulties in classes (for example the difficulty in hearing due to noisy workshop). Also, it benefits the communication and exchanges between teachers and students, and can help to teach students in accordance of their aptitude.

\section{REFERENCES}

[1] Liuli.D.Usability of Visualization Technology in Engineering Course Teaching: Hebei University of Technology.

[2] Wang Zhisen, Zhao Fumin, et al. The Compilation of CNC System Processing Program: Journal of Hefei University of Technology (Natural Science Edition).

[3] Ge Yanjun. (2005:229-248).Key Technology and Application of NC Machining: Beijing Science Press.

[4] Luowei, Zhou Qingbin, et al. (1997).Visual Basic Programming and Application 1001 Questions: Electronic Industry Press.

[5] Ming Zeng. The exploitation of plank stuff furniture's Visual Parametric CAD System Based on VB.[D].Central South Forestry University,2004

[6] Qiang Li.Research of Algorithm Visualization On the Basis of Control Technology.[D].Taiyuan University of Technology,2007

[7] Liu yongbo.Secondary Development of Program Design of AutoCAD Based On VB.[D].University of Electronic Science and technology of China ,2007

[8] Cong Ying jiu.The Design and realization of the refrigeratory testing system based on visual basic.[D].Ocean University of China ,2006

[9] Yu Zhonghai, case teaching applied to the value and implementation strategy of new curriculum [J]. Journal of Tianjin Normal University, 2004, (2) 